\title{
A simple and efficient seed-based approach to induce callus production from B73 maize genotype
}

\author{
Simeon O. Kotchoni ${ }^{1,2 *}$, Pacôme A. Noumavo ${ }^{3}$, Adolphe Adjanohoun ${ }^{4}$, Daniel P. Russo ${ }^{1}$, \\ John Dell'Angelo ${ }^{1}$, Emma W. Gachomo ${ }^{1}$, Lamine Baba-Moussa ${ }^{3}$ \\ ${ }^{1}$ Department of Biology, Rutgers, The State University of New Jersey, Camden, USA \\ ${ }^{2}$ Center for Computational and Integrative Biology (CCIB), The State University of New Jersey, Camden, USA \\ ${ }^{3}$ Département de Biochimie et Biologie Cellulaire, Université d’Abomey-Calavi, Cotonou, Benin \\ ${ }^{4}$ Centre de Recherches Agricoles, Institut National des Recherches Agricoles du Benin, Allada, Benin \\ Email: ${ }^{*}$ simeon.kotchoni@rutgers.edu
}

Received 30 July 2012; revised 30 August 2012; accepted 10 September 2012

\begin{abstract}
The wild type maize genotype, B73, is not amenable for callus production and an efficient protocol for B73 maize callus induction has never been reported up-to-date. Scientific efforts in producing B73 maize callus using all known callus inducible media have been unsatisfactory. Here we developed and described an efficient protocol for callus induction from B73 maize seedlings. The protocol is based on well known callus inducible media CM4C where we have sequentially subtracted some chemical compounds and added some new compounds mediating cell proliferations. This newly described protocol was able to induce callus production in a wide range of crop species including rice and soybean. We found that cell proliferation factors, NAA (auxin analog) and 2,4-D (auxin influx carrier) were not only very crucial but required for positive $B 73$ maize callus induction. The absence of one or the other will lead to the failure of B73 maize callus production. The well known CM4C callus induction composition lacks NAA. Our findings will advance genetic studies of maize mutants generated from $B 73$ genotype background.
\end{abstract}

Keywords: B73 Maize Genotype; Soybean; Callus; CM4C; Maize; Protocol; Rice; NAA; 2,4-D

\section{INTRODUCTION}

Callus production and transformation has been established as a powerful tool to study plant functional genomics, growth regulation, and plant cell morphogenesis. Advances such as callus regeneration from explants and the production of diverse germplasms have provided useful tools for successful crop breeding programs. In

${ }^{*}$ Corresponding author. maize, several different methods have been developed to produce callus from explants. Methods for callus induction from freshly isolated immature embryos [1,2], embryogenic type I [3] and type II [4] have been established for transformation and production of re-generable suspension [5-8] and protoplast cultures [9-12]. It has also been shown that other corn explants such as immature tassels and ears, microspores (anthers), and the base of leaves can produce re-generable cultures and can be used for callus mediated maize transformation [13]. Direct initiation of seedling-derived type I callus cultures, which were similar to immature embryo type I cultures, were produced from callus of several corn genotypes including commercial inbred lines. However for still unknown reasons, production of callus from maize B73 genotype have proven difficult using various known callus induction media and production of B73 callus remains unsatisfactory. This bottleneck has resulted in often utilizing the maize inbred Hi II for the production of maize callus as an alternative to the B73 genotype. In maize, the B73 genotype is the normal/adequate wild genotype representing what Columbia-0 (Col-0) represents in Arabidospsis thaliana. The lack of an appropriate media for efficient production of maize callus using the B73 genotype has hindered our ability to fully use B73 to our advantage. One experimental drawback is an inability to adequately evaluate mutant lines engineered in B73 background.

It is well documented that plant tissue culture and morphogenesis can be improved by the addition of small amounts of certain organic nutrients such as vitamins, amino acids and auxin analogs. The amount of these substances required for successful culture varies by species and genotypes, and is probably a reflection of the explants plasticity under artificial conditions. Cultured plant cells and tissues often become deficient in several biological factors; and the plant tissue cultures growth and survival is improved by their addition to the culture 
medium. For example, myo-inositol (also described as meso-inositol or $i$-inositol) is the only one of the nine theoretical inositol stereoisomers, which has significant biological importance. Medically it is classified as a member of the Vitamin B complex and is required for the growth of yeast and many mammalian cells in tissue culture. Additionally, Morel and Wetmore [14] demonstrated that $100 \mathrm{mg} / \mathrm{l}$ myoinositol in combination with other vitamins could be used to induce callus production from the monocotyledon Amorphophallus rivieri (Araceae). Many other workers have since included it in culture media with favorable results on the rate of callus growth or the induction of morphogenesis. We therefore hypothesized that a carefully adjusted vitamin/nutrient composition of already established callus induced media should be able to produce B73 callus from explants.

Here, we describe an efficient seed-based system for the production of B73 maize callus. The medium is derived from the well established CM4C media [15], where particular nutrient/chemical compounds were omitted and other nutrients added. In order to demonstrate that our method can also be used to induce calli from a wide range of crop species, we tested the new medium in rice (monocot crop) and soybean (dicot crop) callus induction. Moreover, we specifically focused our effort in obtaining optimum experimental conditions, including tips in setting up the media, and the seedling growth conditions to insure a satisfactory and reproducible B73 maize callus production.

\section{MATERIALS AND METHODS}

\subsection{Seed Germination Media and Seed Sterilization}

For germination, seed were first surface-sterilized in 50\% (v/v) bleach, $0.1 \%(\mathrm{v} / \mathrm{v})$ Triton $\mathrm{x}-100$ for 30 minutes, and rinsed with $70 \%$ ethanol for no more than 1 minute, and rinsed again 3 - 4 times with sdd $\mathrm{H}_{2} \mathrm{O}$.

For seed germination on agar media, we dissolved 1 package MS salts with vitamins; $40 \mathrm{~g}$ Maltose; $0.1 \mathrm{~g} \mathrm{Ca-}$ seine hydrolysate; $1.95 \mathrm{~g}$ MES; $0.75 \mathrm{~g} \mathrm{MgCl}_{2}$ in $900 \mathrm{ml}$, and then adjusted the $\mathrm{pH}$ to 5.8 with $2 \mathrm{M} \mathrm{KOH}$. The mixture was then brought to one liter, and $8 \mathrm{~g}$ of agar was added. The medium was autoclaved for 15 - 20 minutes and allowed to cool to $50^{\circ} \mathrm{C}$. To this pre-cooled media, the following (filter sterilized) solutions were added: 0.5 g Glutamine; $0.1 \mathrm{~g}$ Ascorbic acid; $0.5 \mathrm{mg}$ 2,4-D; 0.5 $\mathrm{mg}$ naphthalene acetic acid. Approximately $30 \mathrm{ml}$ of the medium was poured into $100 \times 25 \mathrm{~mm}$ petri-dish and allowed to solidify.

\subsection{Quick and Efficient Seed Germination Alternative}

Alternatively, the surface-sterilized seeds were kept over- night at $4^{\circ} \mathrm{C}$ and then submerged in sterile water in flask covered with mesh cloth allowing aeration as depicted in Figures 1(A) and (B) in order to eliminate the option of agar plate grown seedlings prior to callus inductions. The submerged seeds were kept incubated at room temperature overnight after the water was allowed to drain through the mesh cloth by inverting the flask (Figure 2). In order to keep the seeds wet throughout the germination periods, water was added daily to submerged level, and then allowed to drain after 5 minutes of soaking as described above. The seed germination rate and root length were then recorded. The germinated seeds were successfully used for callus induction.
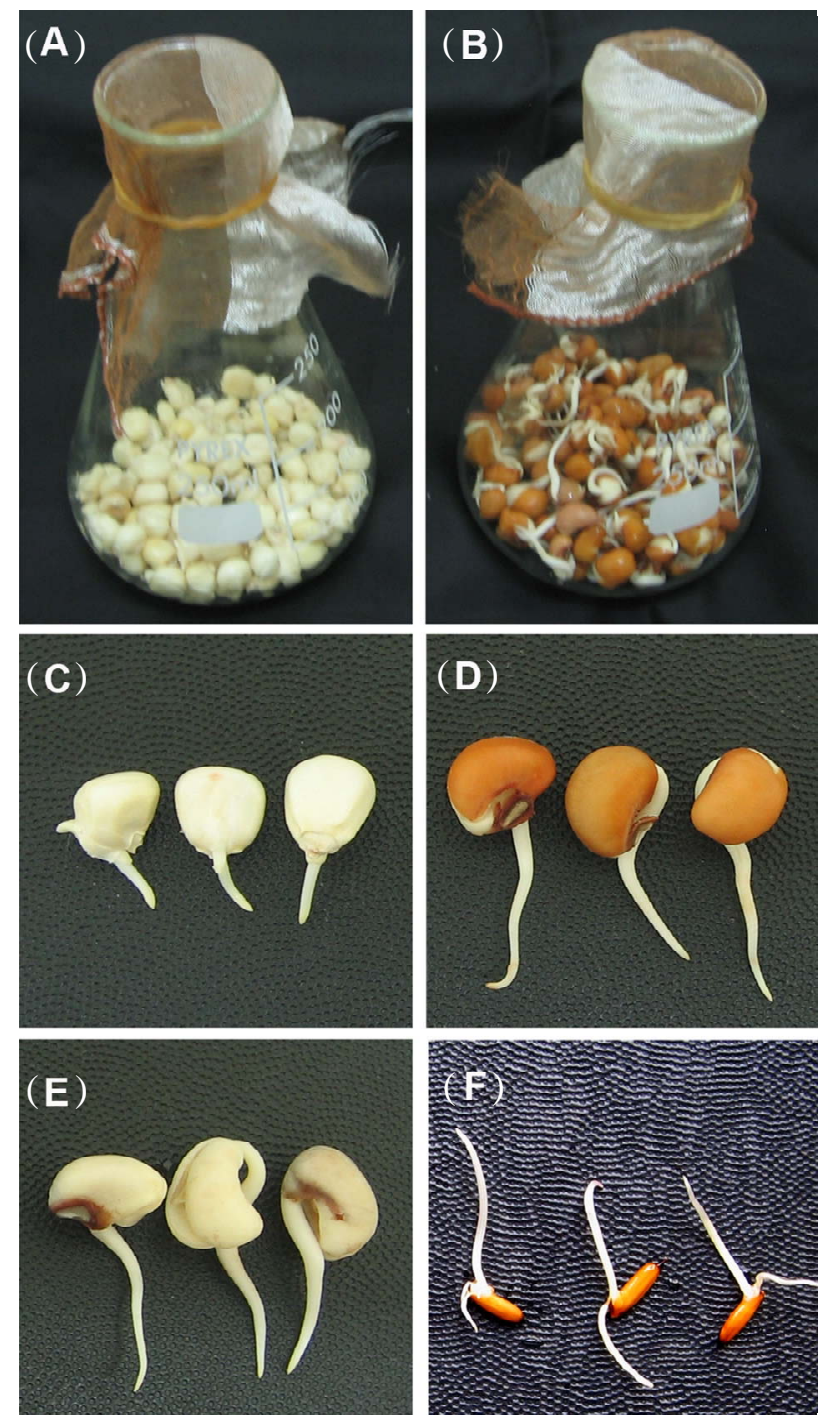

Figure 1. Seed germination growth phenotype on water submerged growth conditions. (A) and (B) Maize (A) and brown soybean (B) seed germination depicted in flasks at 3 days after germination (DAG). (C) Representative germinated maize seeds are depicted at 3 DAG. Representative germinated brown (D) and white (E) soybean seeds are represented at 3 DAG. (F) Representative germinated rice seeds are represented at 5 DAG. 


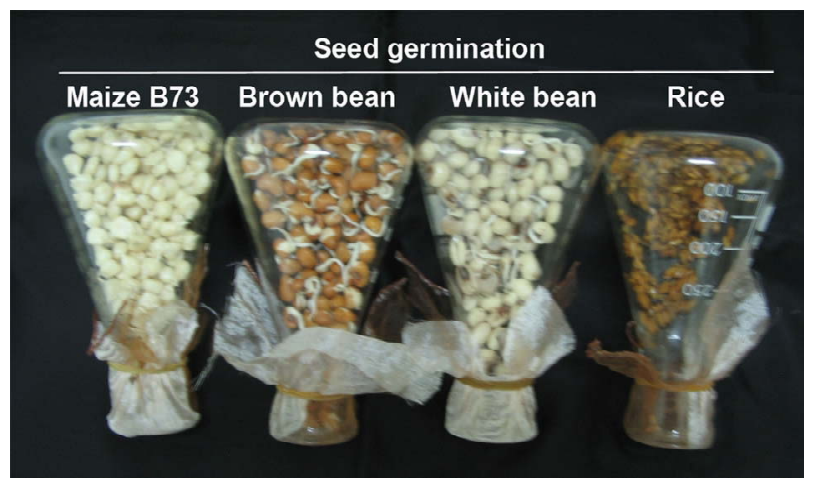

Figure 2. Water submerged seed germination method used for callus induction. Inverted flasks containing germinated seeds (Maize B73, brown soybean, white soybean and rice) are here depicted at 3 days post germination.

\subsection{Callus Induction}

For callus induction, seeds were placed on seed germination media (see above) and grown in the dark (the light grown condition was not satisfactory for B73 maize callus induction) at $28^{\circ} \mathrm{C}-30^{\circ} \mathrm{C}$ for 3 - 5 days, while checking daily for contamination. Seeds were transferred as needed onto fresh media. In these conditions, seeds were expected to germinate in 3 - 5 days. Alternatively, quickly germinated seeds (within 2 - 3 days) from the water submersion approach (as described above) were successfully used to induce callus production as well.

Using aseptic techniques, coleoptiles and all roots were removed from germinated seed as close to the cotyledon as possible. This sectioning gives roughly between $0.5-1 \mathrm{~cm}$ of residual tissue after removal of unwanted tissues. The seedling was then cut longitudinally in half through the middle of the meristematic tissues. Both halves of the seedling were then removed from the endosperm and placed on the freshly prepared callus induction media (modified CM4C media: see Table 1) with the exposed/cut surface down (touching the agar). The agar plate was then incubated in the dark $\left(28^{\circ} \mathrm{C}-30^{\circ} \mathrm{C}\right)$ until the callus was formed. Under this condition, the callus was roughly developed within 5 - 7 days. The callus was then broken away from non-callus tissues and transferred into fresh callus inducible media.

\section{RESULTS AND DISCUSSION}

In our effort to generate and identify maize mutant genotypes resistant to a wide range of pathogen attacks, we initiated a field screen analysis of EMS-mediated mutagenesis of maize population in B73 (wild-type) maize genotype. Several interesting mutants, including highly susceptible and resistant mutants were identified (Figures 3(A)-(F)). Different maize mutants that are highly susceptible to pathogens (Figures 3(B)-(D)), as well as two mutants that are resistant to pathogens (Figures
Table 1. Media composition derived from CM4C-callus inducible media suitable for callus induction from B73 maize genotype.

\begin{tabular}{ccc}
\hline Components & CM4C (amount/L) & $\begin{array}{c}\text { Modified CM4C } \\
\text { (amount/L) }\end{array}$ \\
\hline MS salts & $1 \times$ & $1 \times$ \\
MS vitamins & $1 \times$ & $1 \times$ \\
Caseine hydrolysate & $0.1 \mathrm{~g}$ & $0.1 \mathrm{~g}$ \\
Maltose & $40 \mathrm{~g}$ & $40 \mathrm{~g}$ \\
MES & $1.95 \mathrm{~g}$ & $1.95 \mathrm{~g}$ \\
Magnesium chloride & $0.75 \mathrm{~g}$ & $0.75 \mathrm{~g}$ \\
Glutamine & $0.5 \mathrm{~g}$ & $0.5 \mathrm{~g}$ \\
Ascorbic acid & $0.1 \mathrm{~g}$ & $0.1 \mathrm{~g}$ \\
2,4-D & $0.5 \mathrm{mg}$ & $0.5 \mathrm{mg}$ \\
Picloram & $2.2 \mathrm{mg}$ & - \\
NAA & - & $2.2 \mathrm{mg}$ \\
\hline
\end{tabular}
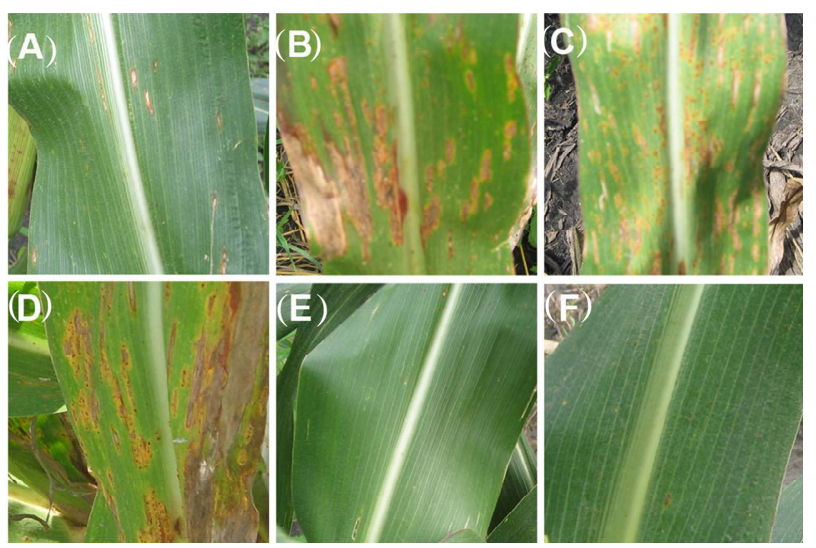

Figure 3. Pathogen susceptible/resistant maize mutants in a field trial. (A) Wild type B73 maize genotype; (B)-(D) Selected mutants susceptible to a wide range of pathogen attacks in the field; (E)-(F) Mutants displaying pathogen resistant phenotype with lack of disease symptoms on the leaves. The mutants were generated from B73 maize genotype background.

3(E)-(F)) in comparison to the wild type B73 (Figure 3(A)) were identified and further analyzed (Kotchoni SO, unpublished). Like these mutants (Figure 3), several other maize mutants have been generated in the maize B73 wild type background [16]. Genetic characterization of these mutants will advance our understanding of plant defense response at the molecular level and how this can be used to improve disease resistance in a wide range of crop species. In order to collect meaningful genetic data using these maize mutants, it is imperative to use B73 maize genotype as the appropriate genetic control. However, up until now, the B73 maize genotype was not amenable to callus induction for genetic study and plant tissue culture regeneration.

In vitro callus culturing is an experimental advanced tool in plant breeding for efficient plant regeneration systems and genetic characterization of a wide range of genotypes in a timely manner [17]. Callus induction and 
regeneration of the whole plants from callus culture is often used in various genetic studies of maize plants $[15,18,19]$. Unlike dicotyledonous species, callus induction and plant regeneration for cereal crops is often difficult. Here we focus our attention on developing a simple and efficient protocol for direct induction of callus from mature B73 maize seed, in order to carry out genetic characterization of our mutants using B73 genotype as the appropriate control. We first hypothesized that well-established callus inducing media used in other plant species might lack the chemical mediating cell proliferation required for callus production in B73 maize genotype. To test our hypothesis, we added and or removed cell proliferation inducible-nutrients/compounds or nutrients/compounds from the well established CM4C callus inducible media $[15,20]$ in a step-wise manner to establish a B73 callus inducible medium and assessed the efficiency of this modified medium to produced B73 maize callus. After a series of additions/removals of chemical compounds, we finally obtained a suitable modified medium composition (Table 1) for callus induction from B73 maize genotype. On this medium the growth of seeds was void of contamination throughout the time of the experiment. The dark grown and not light grown B73 maize seedlings were the only materials that produce better callus under this proposed method (Table 2), although the light growth condition produced callus as well, the quality was not satisfactory. For other crops (rice and soybean) tested in this study, the callus was produced regardless of dark or light grown conditions (Figure 1, Table 2). For seed germination on agar plates, we detected a germination bud that reached $\sim 1 \mathrm{~cm}$ at 5 days after germination (DAG) (Figure 4(A)), and the length of the bud had tripled at 7 DAG. Our data suggested that seedlings be transferred to callus induction media no later than 7 DAG in order to obtain a good callus production. The optimal time to transfer the seedlings to callus induction media is 5 DAG.

As mentioned above, we found that 5 DAG seedlings of dark grown conditions (Figures 4(A)-(D)) were the best source of materials to induce optimum callus production from B73 maize genotype. Even though 7 DAG seedlings were also able to produce callus, their ability to generate suitable callus was far less compared to 5 DAG seedlings. From the 5 DAG seedlings we obtained satisfactory callus production from immature B73 maize plant meristematic tissues (Figure 4). For seedlings grown in submerged water condition, the appropriate time to transfer seedlings into callus induced media was 2 - 3 DAG (Figures 1(C)-(F) and 2). At this time, the germinated bud reached 1 - $2 \mathrm{~cm}$ for maize seedlings and $3-4 \mathrm{~cm}$ for soybeans and rice (Figures 1(C)-(F)).

In order to obtain these results, we modified the CM4C media by replacing picloram with an equivalent amount of NAA (Table 1). Picloram is an herbicide that functions in disrupting normal cell growth leading to uncontrolled and abnormal plant growth, primarily in dicots. NAA is a synthetic analog of auxin that actively diffuses through plasma membranes and acts to stimulate cell proliferation [21]. 2,4-D must be actively imported using auxin influx carriers [22]. Both NAA and 2,4-D are individually less efficient than IAA at inducing the auxin
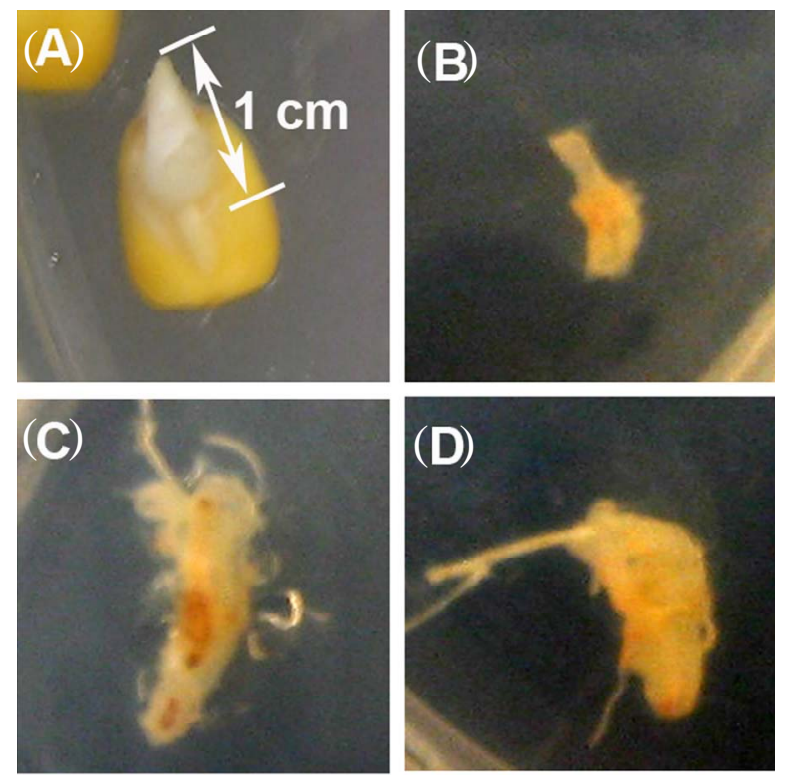

Figure 4. Callus induction from immature B73 maize seedling. (A) 5 DAG agar grown maize seedling used for the callus induction is depicted with $\sim 1 \mathrm{~cm}$ of bud length germination; (B) Callus production at three days post induction; (C) Callus production at five days post induction; (D) Callus production at three days post induction at seven days post induction.

Table 2. Callus induction characteristics from crop seedlings.

\begin{tabular}{ccccc}
\hline Crop species & $\begin{array}{c}\text { DAG in submerged water growth } \\
\text { condition }\end{array}$ & $\begin{array}{c}\text { DAG in agar plate growth } \\
\text { condition }\end{array}$ & $\begin{array}{c}\text { Optimum growth length of } \\
\text { seedling bud }\end{array}$ & Color of the induced callus \\
\hline B73 maize & 3 DAG & 5 DAG & $1 \mathrm{~cm}$ & Yellow and compact \\
B. soybean & 3 DAG & 5 DAG & $2 \mathrm{~cm}$ & Yellow and compact \\
W. soybean & 3 DAG & 5 DAG & $2 \mathrm{~cm}$ & White and compact \\
Rice & 5 DAG & 10 DAG & $2 \mathrm{~cm}$ & White and compact \\
\hline
\end{tabular}

DAG = Days After Germination; B. soybean = Brown soybean; W . soybean $=$ White soybean . 
pathways that lead to cell proliferation and growth, because one (NAA) is too large and the other $(2,4-\mathrm{D})$ is too small to fit the activation sites regulating cell proliferation (Delbarre et al. 1996). However, in combination they probably act synergistically to induce the cell proliferative effect and cause the callus growth. With this modified CM4C media, a better quality of callus and higher growth rate was observed from B73 maize genotype as can be seen in Figures 4(B)-(D).

\section{CONCLUSION}

In this study, we demonstrate for the first time that NAA and 2,4-D are important chemical components without which it will be impossible to induce a callus from B73 maize genotype under our experimental conditions. While picloram concentrations have been used to differentially affect callus induction pattern in a wide range of crop species [23-25], our results indicated that picloram is not necessary for B73 maize callus induction. In fact, we observed no B73 maize callus induction in presence of picloram. Using our developed medium composition (modified CM4C); it was possible to induce callus from B73 maize genotype within 7 DAG. These interesting results merit further investigations. This newly developed medium can be helpful to the scientific community studying maize mutants generated from B73 maize background. This study is a milestone in B73 callus induction and further studies are expected to improve the callus induction properties of this medium.

\section{REFERENCES}

[1] Ishida, Y., Satto, H., Ohta, S., Hiei, Y., Komari, T. and Kumashiro, T. (1996) High efficiency transformation of maize (Zea mays L.) mediated by Agrobacterium tumefaciens. Nature Biotechnology, 14, 745-750. doi:10.1038/nbt0696-745

[2] Songstad, D.D., Armstrong, C.L., Petersen, W.L., Hairston, B. and Hinchee, M.A.W. (1996) Production of transgenic maize plants and progeny by bombardment of $\mathrm{Hi}-\mathrm{II}$ immature embryos. In Vitro Cell Developmental Biology, 32, 179-183.

[3] Wan, Y., Widholm, J.M. and Lemaux, P.G. (1995) Type I callus as a bombardment target for generating fertile transgenic maize (Zea mays L.). Planta, 196, 7-14. doi:10.1007/BF00193211

[4] Walters, D.A., Vetsch, C.S., Potts, D.E. and Lundquist, C. (1992) Transformation and inheritance of a hygromycin phosphotransferase gene in maize plants. Plant Molecular Biology, 18, 189-200. doi:10.1007/BF00034948

[5] Green, C.E., Armstrong, C.L. and Andersen, P.C. (1983) Somatic cell genetic systems in corn. In: Downey, K., Voellmy, R.W., Ahmad, F. and Schultz, J., Eds., Advances in Gene Technology: Molecular Genetics of Plants and Animals, Academic, New York, 147-157.
[6] Vasil, V. and Vasil, I.K. (1986) Plant regeneration from friable embryogenic callus and cell suspension cultures of Zea mays L. Journal of Plant Physiology, 124, 399-408. doi:10.1016/S0176-1617(86)80196-1

[7] Fromm, M.E., Morrish, F., Armstrong, C., Williams, R., Thomas, J. and Klein, T.M. (1990) Inheritance and expression of chimeric genes in the progeny of transgenic maize plants. Biotechnology, 8, 833-839. doi:10.1038/nbt0990-833

[8] Gordon-Kamm, W.J., Spencer, T.M., Mangano, M.L., Adams, T.R., Daines, R.J., Start, W.G., O’Brien, J.V., Chambers, S.A., Adams, W.R., Willetts, N.G., Rice, T.B., Mackey, C.J., Krueger, R.W., Kausch, A.P. and Lemaux, P.G. (1990) Transformation of maize cells and regeneration of fertile transgenic plants. Plant Cell, 2, 603-618.

[9] Rhodes, C.A., Lowe, K.S. and Ruby, K.L. (1988) Plant regeneration from protoplasts isolated from embryogenic maize cell cultures. Biotechnology, 6, 56-60. doi:10.1038/nbt0188-56

[10] Shillito, R.D., Carwell, G.K., Johnson, C.M., Dimaio, J.J. and Harms, C.T. (1989) Regeneration of fertile plants from protoplasts of elite inbred maize. Biotechnology, 7, 581-587. doi:10.1038/nbt0689-581

[11] Morocz, S., Donn, G., Nemeth, J. and Dudits, D. (1990) An improved system to obtain fertile regenerants via maize protoplasts isolated from highly embryogenic suspension culture. Theoretical and Applied Genetics, 80, 721-726. doi:10.1007/BF00224183

[12] Golovkin, M.V., Abraham, M., Morocz, S., Bottka, S., Feher, A. and Dudits, D. (1993) Production of transgenic maize plants by direct DNA uptake into embryogenic protoplasts. Plant Science, 90, 41-52. doi:10.1016/0168-9452(93)90154-R

[13] Cheng, M., Lowe, B.A., Spencer, M., Ye, X. and Armstrong, C.L. (2004) Factors influencing Agro-bacterium-mediated transformation of monocotyledonous species. In Vitro Cell Developmental Biology, 40, 31-45.

[14] Morel, G.M. and Wetmore, R.H. (1951) Tissue culture of monocotyledons. American Journal of Botany, 38, 138140. doi:10.2307/2437836

[15] Cheng, M., Fry, J.E., Pang, S., Zhou, H., Hironaka, C.M., Duncan, D.R., Conner, T.W. and Wan, Y. (1997) Genetic transformation of wheat mediated by Agrobacterium tumefaciens. Plant Physiology, 115, 971-980.

[16] Cartwright, H.N., Humphries, J.A. and Smith, L.G. (2009) PAN1: A receptor-like protein that promotes polarization of an asymmetric division in maize. Science, 323, 649651. doi:10.1126/science. 1161686

[17] Lührs, R. and Lörz, H. (1987) Plant regeneration in vitro from embryogenic cultures of spring- and winter-type barley (Hordeum vulgare L.) varieties. Theorical and Applied Genetics, 75, 16-25. doi:10.1007/BF00249136

[18] Sidorov, V.,'Gilbertson, L.,'Addae, P. and·Duncan, D. (2006) Agrobacterium-mediated transformation of seedlingderived maize callus. Plant Cell Reports, 25, 320-328. doi:10.1007/s00299-005-0058-5

[19] Mélida, H., García-Angulo, P., Alonso-Simón, A., Encina, A., Álvarez, J. and Acebes, J.L. (2009) Novel type II cell 
wall architecture in dichlobenil-habituatedmaize calluses. Planta, 229, 617-631. doi:10.1007/s00425-008-0860-8

[20] Zhou, H., Arrowsmith, J.W., Fromm, M.E., Hironaka, C.M., Taylor, M.L., Rodriguez, D., Pajeau, M.E., Brown, S.M., Santino, C.G. and Fry, J.E. (1995) Glyphosatetolerent CP4 and GOX genes as a selectable marker in wheat transformation. Plant Cell Reports, 15, 159-163. doi:10.1007/BF00193711

[21] Paciorek, T., Zažímalová, E., Ruthardt, N., Petrášek, J., Stierhof, Y.-D., Kleine-Vehn, J., Morris, D.A., Emans, N., Jürgens, G., Geldner, N. and Friml, J. (2005) Auxin inhibits endocytosis and promotes its own efflux from cells. Nature, 435, 1251-1256. doi:10.1038/nature03633

[22] Delbarre, A., Muller, P., Imhoff, V. and Guern, J. (1996) Comparison of mechanisms controlling uptake and accumulation of 2,4-dichlorophenoxy acetic acid, naphtha- lene-1-acetic acid, and indole-3-acetic acid in suspension-cultured tobacco cells. Planta, 198, 532-541. doi:10.1007/BF00262639

[23] Lupotto, E. (1984). Callus induction and plant regeneration from barley mature embryos. Annals of Botany, 54, 523-530.

[24] Machii, H., Mizuno, H., Hirabayashi, T., Li, H. and Hagio, T. (1998) Screening wheat genotypes for high callus induction and regeneration capability from anther and immature embryo cultures. Plant Cell, Tissue and Organ Culture, 53, 67-74. doi:10.1023/A:1006023725640

[25] Mohmand, A.S. and Nabors, M.W. (1991) Comparison of two methods for callus culture and plant regeneration in wheat (Triticum aestivum). Plant Cell, Tissue and Organ Culture, 26, 185-187. 